\title{
Diversidad genética de aislamientos de Bacillus subtilis con potencial para el control biológico de Colletotrichum acutatum y Guignardia citricarpa
}

\author{
Katia Cristina Kupper ${ }^{1}$, Ester Wickert ${ }^{2}$, Ana Paula A. Aukar ${ }^{2}$, Eliana Rivas ${ }^{3}$, Antonio de Goes ${ }^{2}$
}

${ }^{1}$ Centro Apta Citros Sylvio Moreira/IAC, Av. Anhanguera, km 158, 13490-970 Cordeirópolis/SP. ${ }^{2}$ FCAV/UNESP, CEP.14884-900, JaboticabalSP. ${ }^{3}$ Instituto Biológico, CEP 04014-002, São Paulo/SP.

Autor para correspondência: Kátia Cristina Kuppe (katia@ centrodecitricultura.br)

Data de chegada: 30/03/2009. Aceito para publicação em: 28/06/2010.

1651

\section{RESUMEN}

Kupper, K.C., Wickert, E., Aukar, A.P.A., Rivas, E., Goes, A. de. Diversidad genética de aislamientos de Bacillus subtilis con potencial para el control biológico de Colletotrichum acutatum y Guignardia citricarpa. Summa Phytopathologica, v.36, n.2, p.195-202, 2010.

El sector citrícola enfrenta serios problemas representados por enfermedades en las flores y en frutos jóvenes que además de disminuir la productividad, devalúan los frutos por el aspecto que le dan a los mismos. Tales enfermedades están representadas, principalmente, por la mancha negra de los frutos cítricos (MNC) y por la caída prematura de los frutos cítricos (CPFC), donde la medida predominante de control es la pulverización con productos químicos. Entretanto, los costos financieros y ambientales de las aplicaciones con estés productos químicos, sumado a las crecientes restricciones de la presencia de residuos, están a exigir el estudio de nuevas alternativas de control. Entre estas, el control biológico surge como una alternativa importante. Estudios fueron anteriormente realizados, bajo condiciones de laboratorio y de campo, con el objetivo de determinar la potencialidad de aislados de Bacillus subtilis en el control de las enfermedades mencionadas arriba, puesto que, uno aislado, el ACB-69 fue el que presentó la mejor eficiencia de control. Frente a lo anteriormente expuesto y, sabiendo que, el conocimiento de la biodiversidad de los seres es importante para la determinación de sus funciones potenciales, el presente proyecto de investigación tuvo como objetivo estudiar la diversidad genética, a través de marcadores moleculares AFLP, de 32 aislamientos de B. subtilis con la finalidad de se encontrar, dentro los mismos, uno (o más aislados) que presentase mayor semejanza con el ACB-69 y que cuando testado, bajo condiciones naturales de ocurrencia de las enfermedades, si puede encontrar similar control. En función de los resultados experimentales obtenidos, se concluyo que: (a) los aislados de B. subtilis estudiados se agruparon en el filograma de distancia genética, independiente de la procedencia o del huésped; (b) los aislados ACB-69 y ACB-83, con potencial para el control de la caída prematura de los frutos cítricos, comparten la misma ancestralidad, lo que puede ser evaluado por la metodología aplicada; c) en términos biológicos, el aislado ACB-83 merece mas estudios cuanto a la viabilidad de control de las enfermedades caída prematura de los frutos cítricos y de la mancha negra, bajo condiciones de campo.

Palabras-Claves adicionales: Phyllosticta citricarpa, Citrus sinensis, AFLP

\section{RESUMO}

Kupper, K.C., Wickert, E., Aukar, A.P.A, Rivas, E., Goes, A. de. Diversidad genética de aislamientos de Bacillus subtilis con potencial para el control biológico de Colletotrichum acutatum y Guignardia citricarpa. Summa Phytopathologica, v.36, n.2, p.195-202, 2010.

O setor citrícola enfrenta sérios problemas representados por doenças de flores e frutos jovens que, além de diminuir a produtividade, depreciam os frutos pelo aspecto que conferem aos mesmos. Tais doenças são representadas, principalmente, pela mancha preta dos frutos cítricos (MPC) e pela queda prematura dos frutos cítricos (QPFC), onde a medida predominante de controle é a pulverização com produtos químicos. Entretanto, os custos financeiros e ambientais de aplicações com tais produtos, aliado às crescentes restrições à presença de resíduos, estão a exigir o estudo de novas alternativas. Entre estas, o controle biológico surge como alternativa importante. Sabendo-se que, o conhecimento da biodiversidade dos seres vivos é importante para determinação de suas funções potenciais, o presente trabalho teve por objetivo estudar a diversidade genética, através de marcadores moleculares AFLP, de 32 isolados de B. subtilis com a finalidade de se encontrar, dentre os mesmos, um (ou mais isolados) que apresentasse maior similaridade com o isolado ACB-69, o qual apresenta potencial para o controle da doença. Diante disso, os resultados obtidos neste trabalho, permitiram concluir que: a) os isolados de B. subtilis estudados agruparam-se no filograma de distância genética, independente da procedência ou do hospedeiro; b) os isolados ACB-69 e ACB-83, com potenciais para o controle da queda prematura dos frutos cítricos, compartilham da mesma ancestralidade, o que pode ser inferido pela metodologia aplicada; c) em termos biológicos; o isolado ACB-83 merece mais estudos quanto à viabilidade de controle de doenças de citros, como a queda prematura dos frutos cítricos e a manha preta dos frutos cítricos, sob condições de campo.

Palavras-Chave adicionais: Phyllosticta citricarpa, Citrus sinensis, AFLP 
ABSTRACT

Kupper, K.C., Wickert, E., Aukar, A.P.A, Rivas, E., Goes, A. de. Genetic diversity of Bacillus subtilis isolates with potential to biological control of Colletotrichum acutatum and Guignardia citricarpa. Summa Phytopathologica, v.36, n.2, p.107-114, 2010.

The Brazilian citriculture faces with severe problems concerning blooming and young fruit diseases, which cause crop losses and fruit depreciation for market. Such diseases are represented by the postbloom fruit drop (PFD) and by the black spot of citrus (CBS) whose control measures are predominantly through chemical products. However, the economical and environmental disadvantages associated with chemical treatments besides the increasing restrictions on the residuals of pesticides are strong factors that demand new control measures. Among them, the biological control stands out as being an important alternative. Former studies were carried out in laboratory and field conditions aiming at knowing the potentiality of Bacillus subtilis isolates in the control of the above mentioned diseases. Among the tested isolates, the ACB-69 showed the higher control efficiency. This project was undertaken in order to study, by means of AFLP molecular markers, the genetic diversity of 32 isolates of $B$. subtilis with the aim of discovering isolates as efficient as ACB-69, which could show a comparable control when tested under natural conditions of the disease occurrence. It was found from the results gathered here that: (i) the studied isolates of $B$. subtilis were grouped in the phylogram of a genetic distance, regardless of the precedence or host; (ii) the isolates ACB-69 and ACB-83, with potential for the control of the postbloom fruit drop, share the same ancestry, which is inferred by the methodology employed here; (iii) in biological terms, the isolate ACB-83 demands additional studies concerning its feasibility on the control of both diseases in field conditions.

Additional Keywords: Phyllosticta citricarpa, Citrus sinensis, AFLP

El cultivo de la naranja, aunque es cultivado en 108 países, presenta una distribución poco uniforme. Solo Brasil y los Estados Unidos poseen más de la mitad de la producción, quedando el restante dividido entre más de 100 países. Brasil es el mayor productor mundial de naranja, con un área de 881 mil hectáreas, de las cuales $77 \%$ se encuentran localizadas en la región sudeste del país (1).

Cerca del $80 \%$ de la producción de naranja se destina a la industrialización, cuyo jugo producido es exportado para países como Rusia, Bélgica, Países Bajos, Estados Unidos y Japón. Para el Estado de São Paulo, que exporta 95\% de la producción de jugo, este segmento tiene una importancia relevante (1).

No obstante la importancia de este cultivo, el sector citrícola enfrenta serios problemas representados por enfermedades en las flores y en frutos jóvenes que, además de disminuir la productividad, devalúan los frutos por el aspecto que le dan a los mismos. Tales enfermedades están representadas, principalmente, por la mancha negra de los frutos cítricos (MNC) y por la caída prematura de los frutos cítricos (CPFC).

La mancha negra de los cítricos, causada por el hongo Guignardia citricarpa Kiely, fue descrita por primera vez en 1895, en Australia, afectando frutos de naranja 'Valencia', tanto en huertos, como en la fase de poscosecha (13). La enfermedad se encuentra en Australia; en países de África, como Mozambique, Swazilandia y Zimbabwe; en Asia, en países como China, Indonesia, Taiwán y Japón; y en América del Sur, en países como Argentina, Brasil y Perú $(12,13,14,15)$. Su control se basa principalmente en el uso de fungicidas protectores o sistémicos, aisladamente o combinados, asociados o no al aceite mineral $(9,21)$.

La caída prematura de los frutos cítricos, causada por el hongo Colletotrichum acutatum Simmonds se presenta en los trópicos y subtrópicos húmedos de América. En Brasil, la enfermedad fue reportada inicialmente en Rio Grande del Sur (6) y, actualmente, está presente en todos los municipios de São Paulo, además de otros Estados como Rio de Janeiro, Paraná, Bahia, Minas Gerais, Goiás y Amazonas. Condiciones que favorecen más de una floración, o variedades que florezcan más de una vez por año, contribuyen de una manera importante para la aparición de la enfermedad. Por esta razón, en Brasil, la enfermedad es más severa en los limones verdaderos, en lima ácida 'Tahiti', en el limón 'Galego' y en la naranja 'Pera' (7). La medida predominante de control es la pulverización con productos químicos (benzimidazoles) en la época de la floración.

Sin embargo, los costos financieros y ambientales de las aplicaciones con productos químicos, sumado a las crecientes restricciones de la presencia de residuos, exigen el estudio de nuevas alternativas de control. Entre estas, el control biológico surge como una alternativa importante que, además de su coherencia ecológica, en muchos casos, es una tecnología que lleva al ahorro de capital.

Entre los antagonistas mas estudiados, se encuentra la bacteria Bacillus subtilis, la cual se ha destacado en el control de enfermedades del filoplano y en poscosecha $(4,8,11,20,22,27)$.

En Brasil, Kupper \& Gimenes-Fernandes (19) estudiaron la potencialidad antagonística de 64 aislamientos de $B$. subtilis en el control de $C$. acutatum "in vitro" y en flores retiradas de árboles de lima ácida 'Tahiti' . Según los autores, todos los aislamientos produjeron metabolitos capaces de inhibir el crecimiento micelial del fitopatógeno y muchos de ellos dieron $100 \%$ de control de la enfermedad en flores retiradas de lima ácida 'Tahiti'. Entre siete aislamientos de B. subtilis evaluados para el control de la CPFC, en condiciones naturales de ocurrencia de la enfermedad, uno de ellos, el ACB-69, fue diferente del testigo ( in control) y se igualó, estadísticamente, al fungicida benomil, proporcionando un menor porcentaje de flores con síntomas y un mayor número medio de frutos efectivos (20).

Kupper et al. (17) al estudiar cuatro aislamientos de B. subtilis, entre los mencionados arriba, para el control de Guignardia citricarpa, verificaron que los mismos fueron capaces de inhibir el crecimiento micelial del hongo, en cultivo pareado en placa de Petri, con medio papa-destrosa-agar (PDA) y, que el ACB-69 presentó potencialidad para control de la mancha negra de los frutos cítricos, bajo condiciones de campo (18).

Frente a lo anteriormente expuesto y, sabiendo que, el conocimiento de la biodiversidad de los seres vivos es importante para la determinación de sus funciones potenciales, el presente proyecto de investigación tuvo como objetivo estudiar la diversidad genética, a través de marcadores moleculares AFLP, de 32 aislamientos de $B$. subtilis (entre estés el ACB-69), obtenidos a partir de muestras de 
hojas retiradas de huertos de cítricos de diferentes localidades del Estado de São Paulo, con la finalidad de se encontrar, dentre los aislados, uno o más que presentase mayor semejanza con el ACB-69 y que, cuando testado, bajo condiciones de campo, si puede encontrar similar control.

\section{MATERIALES Y MÉTODOS}

El experimento fue implantado y ejecutado en el Laboratorio de Fitopatología del Departamento de Fitosanidad de la Faculdade de Ciencias Agrárias e Veterinárias de la UNESP/Campus de Jaboticabal.

Obtención e identificación de los aislamientos de Bacillus subtilis

Los agentes de control biológico (ACBs) fueron obtenidos a partir de muestras de hojas retiradas de huertos de cítricos en diferentes locales. Fueron utilizados huertos de los municipios de Altinópolis, Itápolis, Jaboticabal, Piracicaba, Taiaçu, Taiúva y Taquaral, todos del Estado de São Paulo (Brasil).

Para la obtención de los aislamientos de Bacillus spp., se adaptó la técnica descrita por Bettiol (3), la cual consiste en el siguiente procedimiento: muestras de hojas obtenidas de plantas al azar en el campo fueron inicialmente lavadas en agua de llave. Después, con el auxilio de un perforador, fueron retirados discos con $10 \mathrm{~mm}$ de diámetro, de la región media, hasta completar un gramo de tejido. Las muestras de hojas fueron colocadas en $100 \mathrm{~mL}$ de agua destilada y esterilizada en Erlenmeyer con capacidad para $250 \mathrm{~mL}$. Los Erlenmeyers, con los respectivos discos de hojas fueron agitados por 1 hora, en agitador mecánico. Después de la agitación, una muestra de $10 \mathrm{~mL}$ fue colocada en un tubo de ensayo y enseguida, fue colocada a baño-maría a $80^{\circ} \mathrm{C}$ durante 10 minutos. Fueron retiradas alicuotas de los tubos de ensayo, para la obtención de diluciones en serie, a razón de $1: 10\left(10^{-1}, 10^{-2}\right.$ y $\left.10^{-3}\right)$ y, $0,2 \mathrm{~mL}$ de la suspensión de cada dilución fue transferido para placas con PDA y esparcida con la ayuda de una asalça de Drigalski. Se hicieron dos placas para cada dilución y cada muestra, y enseguida se incubaron en ambiente de laboratorio. Después de 10 días, se efectuó un examen de las colonias de los microorganismos presentes en las placas, que enseguida, fueron purificadas, identificadas y guardadas en medio de papa-destrosa-agar (PDA) para la realización de estudios posteriores.

Todos los aislamientos de Bacillus spp. obtenidos fueron sometidos a pruebas de morfología celular, reacción de Gram y análisis cualitativa con relación a la presencia de endosporo. Para la identificación de las especies de Bacillus spp. se adoptó un procedimiento semejante al aplicado por Gordon (10), desarrollando pruebas de producción de catalasa, de Voges-Proskauer, de crecimiento en anaerobiosa-agar y de hidrólisis de almidón.

\section{Extracción, cuantificación y calidad del ADN}

EL ADN de los aislamientos bacterianos fue extraído conforme el protocolo de Shillito y Saul (26). En microtubos fueron adicionados $1,5 \mathrm{ml}$ de la solución de cultivo bacteriano, el cual fue centrifugado la 10.000 rpm durante cinco minutos, para la precipitación de las células bacterianas. Después, el sobrenadante fue descartado y el precipitado (pellet) resuspendido en 1,0 $\mathrm{ml}$ de agua destilada para ser lavado. Se realizó una nueva centrifugación para descartar el sobrenadante. Al precipitado (pellet) se le adicionaron $700 \mathrm{~mL}$ de tampón de extracción CTAB (Tris- $\mathrm{HCl}$ pH 7,5 1M; $\mathrm{NaCl} 5 \mathrm{M}$; EDTA pH 8,0 0,5M; CTAB $5 \%$ ), Sarcosyl $10 \%$ y $140 \mathrm{nM}$ de $B$-mercaptoetanol). Se adicionaron también $5 \mathrm{~mL}$ de RNAsa $(10 \mathrm{mg} / \mathrm{ml})$. Los tubos se agitaron para homogenización y después fueron incubados en baño-maría a $65^{\circ} \mathrm{C}$ durante 1 hora, agitándose suavemente cada 15 minutos. Después de la incubación, los tubos se dejaron por 5 minutos a temperatura ambiente $\mathrm{y}$, enseguida, se adicionaron $700 \mathrm{~mL}$ de cloroformo/alcohol isoamílico (24:1), agitando suavemente durante 5 minutos. Los tejidos celulares se removieron por centrifugación a 10.000 rpm por 10 minutos a $20^{\circ} \mathrm{C}$, adicionando nuevamente $700 \mathrm{~mL}$ de cloroformo/octanol (24:1) y nuevamente se removieron los restos celulares por centrifugación a $10.000 \mathrm{rpm}$ por 10 minutos a $20^{\circ} \mathrm{C}$. A la fase superior colectada se le adicionó 0,1 volumen de CTAB $10 \%$ y se repitió la extracción con cloroformo/alcohol isoamílico (24:1). El sobrenadante fue retirado y se adicionó 1 volumen de tampón de precipitación CTAB (Tris- $\mathrm{HCl}$ pH 7,5 1M; EDTA pH 8,0 0,5M; CTAB 1\%), así fue dejado en reposo por 60 minutos. Se centrifugó por 4 minutos a $10.000 \mathrm{rpm}$ y se descartó el sobrenadante. El sedimento se disolvió en $400 \mathrm{~mL}$ de TE alto sal (Tris-HCl pH 7,5 1M; $\mathrm{NaCl} 5 \mathrm{M}$; EDTA pH 8,0 0,5M) y se agitó hasta su total disolución. El $\mathrm{ADN}$ se precipitó, adicionándosele 2 volúmenes de etanol absoluto helado, así permaneció overnight a $20{ }^{\circ} \mathrm{C}$. Paso a seguir, el ADN fue centrifugado a $12.000 \mathrm{rpm}$ durante 20 minutos a $4^{\circ} \mathrm{C}$ y el sobrenadante se descartó. Se realizaron dos aplicaciones sucesivas de $700 \mathrm{~mL}$ de etanol $70 \%$ y etanol absoluto, seguidas por centrifugaciones a $12.000 \mathrm{rpm}$ durante 20 minutos a $4^{\circ} \mathrm{C}$ y el sobrenadante se descartó. El precipitado formado se secó y luego se resuspendió en $100 \mathrm{~mL}$ de Tampón TE $(0,01 \mathrm{M}$ TRIS pH 8,0 y $0,001 \mathrm{M}$ EDTA $\mathrm{pH} 8,0$ ) por 2 horas a temperatura ambiente. La cuantificación del ADN y la evaluación de su calidad fue realizada con auxilio de un espectrofotómetro, midiéndose la absorbancia de cada muestra en contraste con una muestra de $\mathrm{H}_{2} \mathrm{O}$ destilada libre de ADN, en las longitudes de onda de 260 y $280 \mathrm{~nm}$ (25). La calidad del ADN fue verificada durante su cuantificación observando la relación encontrada entre las lecturas en las longitudes de onda de 260 y 280 $\mathrm{nm}$, que debe ser entre 1,8 y 2,0, lo que caracteriza un $\mathrm{ADN}$ de buena calidad.

\section{Desarrollo de los marcadores fAFLP}

Este procedimiento se llevó las siguientes etapas:

\section{Restricción}

Preparación del "Enzyme Master Mix"

La siguiente mezcla fue realizada en un tubo de $0,5 \mathrm{~mL}: 0,1 \mathrm{~mL}$ del tampón React1 de la enzima EcoRI, 0,1 mL 0,5 M NaCl, 0,05 mL $1 \mathrm{mg} / \mathrm{mL}$ BSA, 1 Unidad MseI, 5 Unidades EcoRI. Se usaron preparaciones con concentraciones altas de enzimas para evitar el exceso de $5 \%$ de glicerol en las reacciones. Se adicionó agua estéril destilada completando el volumen para $1 \mathrm{~mL}$, mezclando gentilmente, precipitándolo enseguida en una micro-centrífuga por $10 \mathrm{seg}$, y guardado posteriormente en hielo. Para obtener mejores resultados se usó "enzyme master mix" durante 1-2 horas, sin poderlo guardar mas allá del día en que fue preparado.

\section{Reacciones de restricción}

La reacción de restricción preparó el molde para los adaptadores, uniendo el par de adaptadores al ADN molde ya preparado. Se hizo la siguiente mezcla en un tubo de 0,5 mL: 1,0 mL del tampón React 1 de la enzima EcoRI, 1,0 mL 0,5 M NaCl libre de nucleasa, 0,5 mL 1,0 mg/ $\mathrm{mL}$ BSA libre de nucleasa, 2,0 mL de agua milli-Q autoclavada libre de nucleasa, 1,0 mL del "enzyme master mix" anteriormente preparado y (500 ng) de ADN genómico de cada uno de los aislamientos, resuspendido en 5,5 mL de agua milli-Q autoclavada. Se hizo una mezcla y se precipitó en una microcentrífuga por 10 segundos, 
incubando posteriormente por 15 horas a $37^{\circ} \mathrm{C}$. Después se corrió un gel de agarosis $1,5 \%$ para verificar si la restricción de las muestras había ocurrido.

\section{Unión de los adaptadores}

De los tubos que contenían el par adaptador de la MseI y el par adaptador de la EcoRI, se retiró una alícuota de $0,25 \mathrm{~L}$ de cada adaptador, colocándolos en tubos separados y calentándolos en el termociclador a $95^{\circ} \mathrm{C}$ por $5 \mathrm{~min}$, enfriando enseguida a temperatura ambiente por un período superior a $10 \mathrm{~min}$, precipitándolos en una micro-centrífuga por $10 \mathrm{seg}$ a $1400 \mathrm{~g}$ y mezclando los dos adaptadores en un único tubo. Se preparó una mezcla que contenía: $0,75 \mathrm{~mL}$ del tampón 10x T4 ADN Ligasa con ATP, 0,375U de T4 ADN Ligasa y $0,5 \mathrm{~mL}$ de los adaptadores previamente pareados. Se mezcló 1,625 $\mathrm{mL}$ de la mezcla anterior con $2,375 \mathrm{~mL}$ de la muestra previamente digerida, dejando por 2 horas a $20^{\circ} \mathrm{C}$ en un termociclador y enseguida se diluyeron las reacciones de ligación en TE.

\section{Diluición de las reaciones de ligacción}

Las muestras de $\mathrm{ADN}$ se diluyeron ya digeridas por las enzimas y unidas a los adaptadores, para dar la concentración apropiada para el PCR subsiguiente. Fueron adicionados $46 \mathrm{ml}$ de tampón TE 0,1M en cada reacción digerida-unida, mezclando completamente.

\section{Amplificación preselectiva}

Las secuencias con los adaptadores unidos en las de los extremidades amplifican exponencialmente y predominan en el producto final. Todos los reactivos y tubos fueron mantenidos en el hielo hasta el momento de la amplificación. Se hizo una mezcla en un tubo para la reacción de PCR así: 2,0 $\mathrm{mL}$ del ADN diluido preparado a partir de las reacciones de restricción y unión, $0,5 \mathrm{~mL}$ de la mezcla de los primers preselectivos AFLP EcoRI y MseI y 7,5 mL del AFLP Core Mix. Las muestras se colocaron en un termociclador a temperatura ambiente, corriendo el siguiente programa de PCR: calentamiento inicial a $72^{\circ} \mathrm{C} / 2 \mathrm{~min}$., seguido de 20 ciclos de $94^{\circ} \mathrm{C} / 20$ s., $56^{\circ} \mathrm{C} / 30 \mathrm{~s}, 72^{\circ} \mathrm{C} /$ $2 \mathrm{~min}$., terminando a $4^{\circ} \mathrm{C}$.

Las muestras fueron almacenadas por 2 a $6^{\circ} \mathrm{C}$ después de la amplificación preselectiva.

\section{Verificación del éxito de la amplificación preselectiva.}

En un gel de agarosis se confirmó la amplificación preselectiva, para esto $5 \mathrm{~mL}$ de cada reacción de amplificación preselectiva fue aplicada en un gel de agarosis 1,5\% en tampón 1x TEB en $4 \mathrm{~V} / \mathrm{cm}$ por 3-4 horas. Al gel se le aplicó brometo de etídio para la coloración y se observó en un transiluminador con UV.

\section{Amplificación selectiva}

Para el preparo de la amplificación selectiva se adicionó a un tubo estéril de 0,5 mL: 2,5 mL del producto de la reacción de amplificación preselectiva y 47,5 mL de tampón TE $0,1 \mathrm{M}$. Se mezcló completamente, y entonces se precipitó por 10 seg en una micro-centrífuga.

Después de la selección de los cebadores, para la reacción de PCR, se hizo la combinación de los siguientes componentes en un tubo tipo eppendorf de 0,2 mL: 0,75 mL del producto de la reacción de amplificación preselectiva, 0,25 L del MseI, 0,25 mL del EcoRI (marcado por fluorescencia) y 3,75 mL del AFLP Core Mix. Después se hizo la corrida de un PCR usando los parámetros del termociclador indicados en la Tabla 1. El producto de la amplificación selectiva se almacenó a $2-6^{\circ} \mathrm{C}$.
Tabla 1 - Parámetros usados en el termociclador durante la amplificación selectiva.

\begin{tabular}{ccccc}
\hline $\begin{array}{c}\text { Calentamiento } \\
\text { inicial }\end{array}$ & & Ciclo & $\begin{array}{c}\text { Número } \\
\text { de Ciclos }\end{array}$ \\
\hline $94^{\circ} \mathrm{C} 2 \mathrm{~min}$ & $94^{\circ} \mathrm{C} 60 \mathrm{seg}$ & $66^{\circ} \mathrm{C} 60 \mathrm{seg}$ & $72^{\circ} \mathrm{C} 2 \mathrm{~min}$ & 1 \\
- & $94^{\circ} \mathrm{C} 60 \mathrm{seg}$ & $65^{\circ} \mathrm{C} 60 \mathrm{seg}$ & $72^{\circ} \mathrm{C} 2 \mathrm{~min}$ & 1 \\
- & $94^{\circ} \mathrm{C} 60 \mathrm{seg}$ & $64^{\circ} \mathrm{C} 60 \mathrm{seg}$ & $72^{\circ} \mathrm{C} 2 \mathrm{~min}$ & 1 \\
- & $94^{\circ} \mathrm{C} 60 \mathrm{seg}$ & $63^{\circ} \mathrm{C} 60 \mathrm{seg}$ & $72^{\circ} \mathrm{C} 2 \mathrm{~min}$ & 1 \\
- & $94^{\circ} \mathrm{C} 60 \mathrm{seg}$ & $62^{\circ} \mathrm{C} 60 \mathrm{seg}$ & $72^{\circ} \mathrm{C} 2 \mathrm{~min}$ & 1 \\
- & $94^{\circ} \mathrm{C} 60 \mathrm{seg}$ & $61^{\circ} \mathrm{C} 60 \mathrm{seg}$ & $72^{\circ} \mathrm{C} 2 \mathrm{~min}$ & 1 \\
- & $94^{\circ} \mathrm{C} 60 \mathrm{seg}$ & $60^{\circ} \mathrm{C} 60 \mathrm{seg}$ & $72^{\circ} \mathrm{C} 2 \mathrm{~min}$ & 1 \\
- & $94^{\circ} \mathrm{C} 60 \mathrm{seg}$ & $59^{\circ} \mathrm{C} 60 \mathrm{seg}$ & $72^{\circ} \mathrm{C} 2 \mathrm{~min}$ & 1 \\
- & $94^{\circ} \mathrm{C} 60 \mathrm{seg}$ & $58^{\circ} \mathrm{C} 60 \mathrm{seg}$ & $72^{\circ} \mathrm{C} 2 \mathrm{~min}$ & 1 \\
- & $94^{\circ} \mathrm{C} 60 \mathrm{seg}$ & $57^{\circ} \mathrm{C} 60 \mathrm{seg}$ & $72^{\circ} \mathrm{C} 2 \mathrm{~min}$ & 1 \\
- & $94^{\circ} \mathrm{C} 30 \mathrm{seg}$ & $56^{\circ} \mathrm{C} 30 \mathrm{seg}$ & $72^{\circ} \mathrm{C} 2 \mathrm{~min}$ & 20 \\
$60 \mathrm{C}$ & & & & 1 \\
$30 \mathrm{~min}$ & & & & \\
\hline
\end{tabular}

Aplicación de las muestras y eletroforese en el ABI PRISM 377 ADN Sequencer

Se preparó una mezcla que contenía: $0,625 \mathrm{~mL}$ de "loading solution", 1,25 mL de formamida desionizada, $0,125 \mathrm{~mL}$ del patrón interno de peso molecular GeneScan-500 [ROX] marcado por fluorescencia con color rojo. El producto de la amplificación selectiva fue previamente calentado a $95^{\circ} \mathrm{C}$ por 3 minutos y en seguida colocado rápidamente en hielo. Se retiró una alícuota de $1,0 \mathrm{~mL}$ y se mezcló con $2,0 \mathrm{~mL}$ de la mezcla preparada anteriormente. Se aplicó $1,0 \mathrm{~mL}$ de cada muestra en un gel 5\% desnaturante Long Ranger usando TEB 1X como tampón de corrida. Se utilizó una placa de secuenciamiento de $36 \mathrm{~cm}$, y 2,5 horas de tiempo de corrida, a $2500 \mathrm{~V}$, ccd $4 \mathrm{n}$ en un secuenciador automático de $\mathrm{ADN}$ (ABI Prism 377). El patrón interno de peso molecular GeneScan-500 [ROX] usado en el fAFLP fue marcado por fluorescencia con el color rojo (ROX), contando con 15 fragmentos con las siguientes longitudes (nt): 50, 75, 100, 139, 150, 160, 200, 250, 300, 340, 350, 400, 450, 490 y 500. Entre los cebadores evaluados, se seleccionaron los que presentaron mejor amplificación, los cuales fueron: -Fam EcoRI LA-MseIG, Ned Eco RI C-MseIG y Joe EcoRI G- MseIC.

\section{Análisis de los datos}

Para analizar el gel fueron utilizados para la colecta de los datos y la transformación de los mismos en una matriz binaria, los programas GeneScan (ABI Prism) y Genotyper (ABI Prism), La matriz binaria generada se analizó en el programa PAUP (Phylogenetic Analysis Using Parcimony - verson3.01) (28) para generar la matriz de distancia.

\section{Calculo de las distancias entre los grupos}

La matriz de distancia gerada fue utilizada entre aislados divididos de acuerdo con su origen geográfica. Las distancias genéticas fueran calculadas en el programa MEGA y representarán una medida de la diversidad genética existente entre los aislados. Fueran calculadas la media de la distancia genética entre todos los aislados de este estudio, la media de la distancia entre los aislados pertenecientes a una misma región geográfica y la media de la distancia genética entre los diferentes grupos. 
Tabla 2- Aislados de Bacillus subtilis obtenidos de hojas de plantas cítricas, en municipios del Estado de São Paulo, Brasil.

\begin{tabular}{llllll}
\hline Aislado & Planta huésped & Procedencia & Aislado & Planta huésped & Procedencia \\
\hline ACB-12 & Naranja 'Pêra' & Jaboticabal & ACB-66 & Naranja 'Valência' & Itápolis \\
ACB-16 & Naranja 'Pêra' & Taquaral & ACB-69 & Naranja 'Valência' & Itápolis \\
ACB-18 & Naranja 'Pêra' & Taiúva & ACB-70 & Naranja 'Valência' & Itápolis \\
ACB-19 & Naranja 'Pêra' & Taiúva & ACB-71 & Naranja 'Pêra' & Jaboticabal \\
ACB-25 & Naranja 'Pêra' & Taiúva & ACB-73 & Naranja 'Pêra' & Jaboticabal \\
ACB-27 & Naranja 'Pêra' & Taiúva & ACB-75 & Naranja 'Pêra' & Jaboticabal \\
ACB-44 & Lima ácida 'Tahiti' & Itápolis & ACB-76 & Naranja 'Pêra' & Jaboticabal \\
ACB-45 & Lima ácida 'Tahiti' & Itápolis & ACB-77 & Naranja 'Pêra' & Jaboticabal \\
ACB-48 & Lima ácida 'Tahiti' & Itápolis & ACB-83 & Naranja 'Pêra' & Taiaçu \\
ACB-51 & Naranja 'Pêra' & Itápolis & ACB-85 & Naranja 'Pêra' & Taiaçu \\
ACB-52 & Naranja 'Pêra' & Itápolis & ACB-86 & Naranja 'Pêra' & Taiaçu \\
ACB-53 & Naranja 'Pêra' & Itápolis & ACB-87 & Naranja 'Pêra' & Taiaçu \\
ACB-54 & Naranja 'Pêra' & Itápolis & ACB-88 & Naranja 'Pêra' & Taiaçu \\
ACB-57 & Naranja 'Pêra' & Itápolis & ACB-90 & Naranja 'Pêra' & Altinópolis \\
ACB-60 & Naranja 'Pêra' & Itápolis & ACB-91 & Naranja 'Pêra' & Taiaçu \\
ACB-63 & Naranja 'Valência' & Itápolis & AP-3 & solo & Piracicaba \\
\hline
\end{tabular}

\section{Construcción del filograma}

La matriz de distancia obtenida se analizó en el programa MEGA ((verson2.1) (16), utilizando el Método de Distancia con algoritmo de agrupamiento de Neighbour Joining (24) para la construcción del filograma de las relaciones filogenéticas desarrolladas por los aislamientos.

\section{RESULTADOS Y DISCUSIÓN}

\section{Obtención e identificación de aislados de Bacillus subtilis}

Los aislados de Bacillus subtilis, fueron obtenidos en diferentes regiones productoras de cítricos en el Estado de São Paulo y se encuentran relacionados en la Tabla 2. Se observó que todos los aislados de la bactéria, obtenidos de hojas de cítricos, presentarán reacción Gram positiva, presencia de endósporo, células en forma de bastonetes y agrupamientos de las células a los pares o en cadenas.

Con relación a las pruebas bioquímicas, se constató que los aislados presentarán reacción positiva a la producción de catalase, al test de Voges-Proskauer, crescimiento en aerobiose-ágar y reacción positiva a la hidrólise de amido. Por lo tanto, se pueden considerar como perteneciendo a la misma espécie, Bacillus subtilis, de acuerdo con la llave de identificación de Gordon (10).

\section{Reacciones de AFLP}

Por los resultados presentados en la Tabla 3, se pudo constatar

Tabla 3- Cálculo de la media de distancia entre los aislados oriundos a una misma región geográfica

\begin{tabular}{cc}
\hline Región geográfica & Media de la distancia genética \\
\hline Piracicaba & $\mathrm{n} / \mathrm{c} *$ \\
Taiuva & 0,1897 \\
Itápolis & 0,0690 \\
Jaboticabal & 0,0828 \\
Taquaral & $\mathrm{n} / \mathrm{c}$ \\
Taiaçu & 0,1241 \\
Altinópolis & $\mathrm{n} / \mathrm{c}$ \\
* Media de la distancia genética de todos los aislados: $0,09365 * \mathrm{n} / \mathrm{c}:$ no calculado
\end{tabular}

* Media de la distancia genética de todos los aislados: 0,09365. *n/c: no calculado que, la menor diversidad genética $(0,0690)$ fue observada entre los aislados del grupo de Itápolis, mientras que, la mayor diversidad genética fué obtenida entre los aislados del grupo de Taiúva $(0,1897)$.

Cuando se analizaron los datos de la Tabla 4, se observó que el aislado de Taquaral (ACB-16) con el aislado de Altinópolis (ACB-90) no presentan entre ellos diversidad genética, pudiendo ser considerados como siendo los mismos aislados, de acuerdo con los métodos utilizados.

Con relación a los aislados de Taiúva y los de Taiaçú, se observó que, presentaron de acuerdo con la Tabla 4, a mayor distancia genética $(0,1609)$ observada, indicando que se trataban, aparentemente, de aislados con grande diversidad genética, a pesar de su proximidad geográfica.

La mayor distancia genética observada entre los aislados de Taiúva y Taiaçú (Tabla 4) se debe al tamaño de los ramos obtenidos respectivamente para los aislados ACB-19 y ACB-86 (Figura 1). Como los valores de la Tabla 4 fueron calculados con base en las medias de las distancias, puede haber ocurrido un "mascaramiento" de la distancia real entre los aislados, sin embargo esto fue corregido por la análisis de distancia presentada en la Figura 1, una vez que, en la misma fue computado cada uno de los aislados individualmente.

Cuando se comparan los aislados de Taquaral (ACB-16) e Altinópolis (ACB-90), podemos observar que ambos están en el mismo sub-grupo de aislados de Taiúva (ACBs 18, 25 e 27), Itápolis (ACBs 44, 48, 51, 53, 54, 57, 66 e 70), Jaboticabal (ACBs 12 e 76) e Taiaçú (ACB-91), mostrando que, estos aislados dividen la misma ancestralidad y presentan una distancia genética despreciable entre ellos.

Se observó que, la misma región geográfica, como por ejemplo Taiaçu, presenta una gran diversidad de aislados, presentando ejemplares en prácticamente todos los sub-grupos (Figura 1). Por otro lado, se puede verificar que existen aislados idénticos, sin embargo ampliamente diseminados en diferentes regiones, como se observa dentro del sub-grupo I, donde 17 aislados presentaran distancia nula o irrisoria

Un dato aparentemente conflictivo puede ser ilustrado por el grupo de aislados de Itápolis, una vez que, de acuerdo con la Tabla 3, este 
Tabla 4- Cálculo de la media de distancia genética entre los grupos de diferentes regiones geográficas.

\begin{tabular}{|c|c|c|c|c|c|c|c|}
\hline & Piracicaba & Taiuva & Itápolis & Jaboticabal & Taquaral & Taiaçu & Altinópolis \\
\hline Piracicaba & - & & & & & & \\
\hline Taiuva & 0,1293 & - & & & & & \\
\hline Itápolis & 0,0690 & 0,1293 & - & & & & \\
\hline Jaboticabal & 0,0805 & 0,1408 & 0,0734 & - & & & \\
\hline Taquaral & 0,0345 & 0,0948 & 0,0345 & 0,0460 & - & & \\
\hline Taiaçu & 0,1034 & 0,1609 & 0,0981 & 0,1073 & 0,0690 & - & \\
\hline Altinopolis & 0,0345 & 0,0948 & 0,0345 & 0,0460 & 0,0000 & 0,0690 & - \\
\hline
\end{tabular}
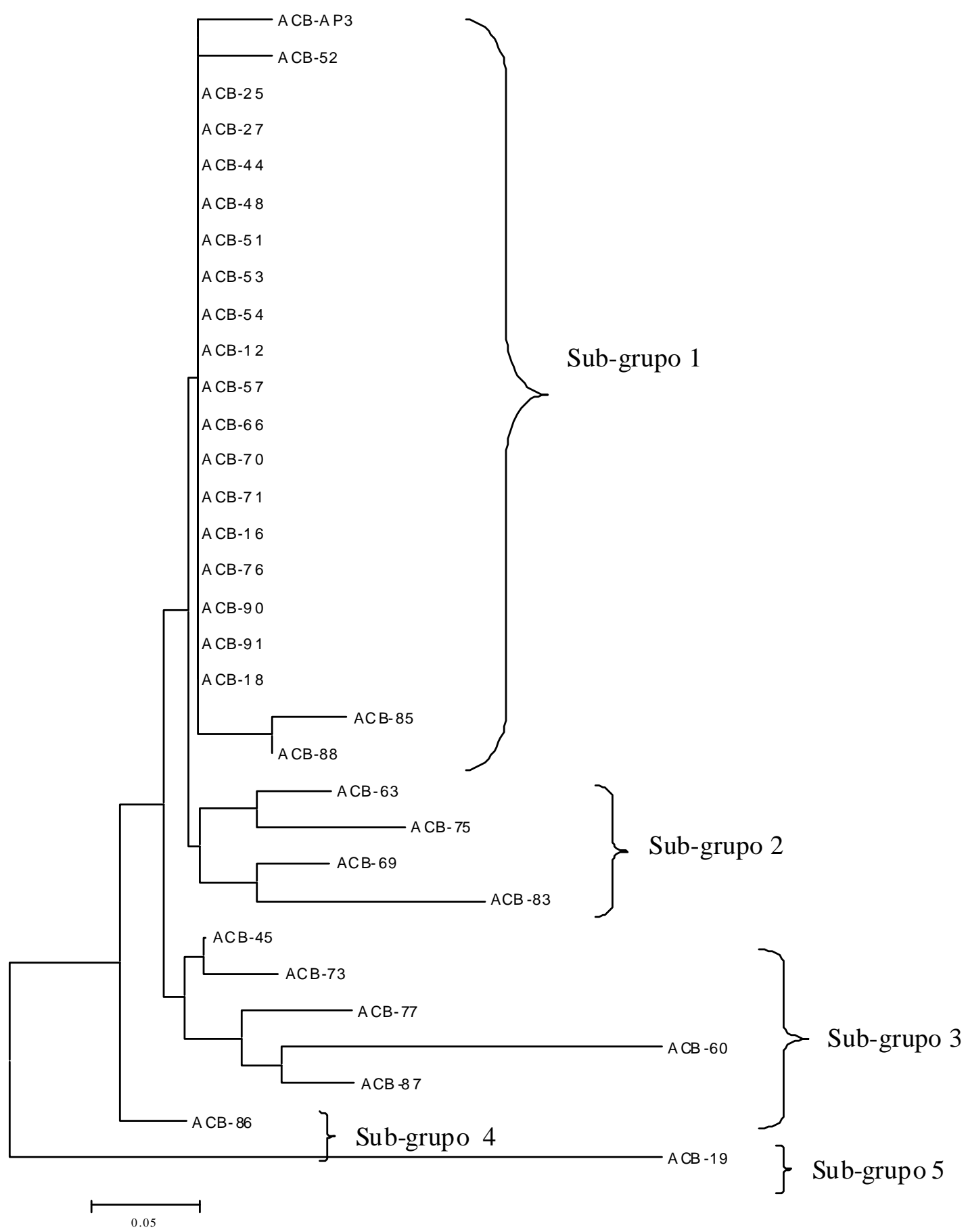

Sub-grupo 5

Figura 1 - Filograma mostrando la distância genética entre los 32 aislados de B. subtilis. 
grupo presentó una menor diversidad intraespecífica, mientras que por la Figura 1, se observa la presencia de aislados de la región en diferentes sub-grupos. Posiblemente, los ocho aislados idénticos o que se asemejan mucho (ACBs-44, 48, 51, 53, 54, 57, 66 e 70) presentes en el sub-grupo I desviaran la media o maquillaron la real diversidad existente. Hecho similar puede ser relatado cuando se analizaron separadamente los aislados dentro del grupo de Taiaçú y de Taiúva, donde ACB-86 e ACB-19, respectivamente, presentaron mayores diversidades genéticas (cuando comparado con los demás aislados de cada región).

El hecho es que los diferentes aislados se agruparon en el filograma de distancia genética, independientemente de su procedencia o huésped y, que la metodología aplicada fue adecuada pues permitió solucionar cuestiones genéticas de cerca del $50 \%$ de los aislados analizados.

El ACB-69 y ACB-83 fueron los aislados que in vivo presentaran $100 \%$ de control al C. acutatum (19), cuando flores retiradas de citros fueron tratadas con los agentes de biocontrol 24 horas antes de la inoculación con el fitopatógeno. Un hecho interesante fue que ambos aislados comparten el mismo ancestral (Figura 1), lo que puede ser corroborado por la metodología aplicada.

De acuerdo con Restrepo et al. (23), una baja correlación entre las similaridades encontradas con RFLP y AFLP fue observada para la bacteria fitopatogénica Xanthomonas axonopodis pv. manihotis. Sin embargo, los autores observaran que, dendogramas generados con datos de AFPL fueron mas indicados para estudios filogenéticos. En otro estudio, los resultados obtenidos con una colección mundial de $X$. axonopodis pv. citri por BOX y ERIC-PCR (5) y con AFLP (2) sugirieron una baja variabilidad genética, en termos filogenéticos, de aislados de este patógeno. Baja variabilidad genética, en termos filogenéticos, a partir de datos generados por la técnica de AFLP, también fue observada para 17 de los 32 aislados utilizados en este estudio, conforme muestra la Figura 1.

A pesar de las ventajas de la técnica con AFLP, como velocidad y practicidad en la detección de polimorfismos vía reacción PCR, necesidad de pequeñas cantidades de DNA, y todavía ser una técnica altamente reproducible, los resultados obtenidos por los marcadores AFLP pueden variar dependiendo del método de análisis seleccionado (Tabla 4 y Figura 1), como observado en este trabajo. De una manera general, una limitación de las técnicas basadas en PCR, como AFPL, y la posibilidad de que, aislados con secuencias geonómicas diferentes puedan tener el mismo número de sitios de restricción de las enzimas, resultando en un número de fragmentos iguales y de tamaños similares, pudiendo de esta manera ser evaluados como "el mismo aislado". Este hecho que puede haber ocurrido con los 17 aislados citados arriba, como siendo del mismo tamaño y supuestamente considerados como siendo el mismo aislado.

Los resultados de este trabajo sugieren que, en termos biológicos, el aislado ACB-83 merece mas estudios cuanto a la viabilidad de control de las enfermedades en estudio, junto con el ACB-69. La combinación de los dos agentes de bicontrol, incluso, visando una acción sinergistíca de los microorganismos, podría elevar la eficiencia de control y, consecuentemente, los datos podrían auxiliar en la elaboración de un producto comercial compuesto por los dos aislados.

No existen resultados cuanto a la eficacia de control, sobre condiciones de campo, del aislado ACB-83, tanto para C. acutatum como para G. citricarpa. Sin embargo las hay en condiciones de laboratorio y en flores destacadas, el aislado fue efectivo contra C. acutatum, agente causal de la caída prematura de los frutos cítricos (19).

El nivel de similitud se observó en más del 50\% de los aislados evaluados. Sin embargo, el uso de la técnica de marcadores moleculares
AFLP para el estudio de la diversidad genética fue adecuado, pues permite la identificación y discriminación de los cinco grupos diferentes de los aislados, caracterizado por el alto grado de polimorfismo. La metodología utilizada permitió la selección de un grupo de aislados que tienen características similares, como por ejemplo, el antagonismo a los patógenos presentado por los aislados ACB-69 y ACB-83.

\section{REFERÊNCIAS BIBLIOGRÁFICAS}

1. Agrianual 2005: Anuário da Agricultura Brasileira. São Paulo: FNP, 2005. p. 248.

2. Belasque Junior., J. Dinâmica espacial do cancro cítrico, interação com a larva minadora dos citros (Phyllocnistis citrella) e diversidade genética do seu agente causal (Xanthomonas axonopodis pv. citri). 2005. 171f. Tese (Doutorado em Fitopatologia) - Escola Superior de Agricultura "Luiz de Queiroz", Universidade de São Paulo, Piracicaba.

3. Bettiol, W. Isolamento seletivo de Bacillus. In: Melo, I.S. de; Sanhueza, R.M.V. Métodos de seleção de microrganismos antagônicos a fitopatógenos. Jaguariúna: Embrapa, CNPMA, 1995. p.35-36.

4. Bettiol, W.; Saito, M. L.; Brandão, M. S. B. Controle da ferrugem do cafeeiro com produtos a base de Bacillus subtilis. Summa Phytopathologica, Jaguariúna, v. 20, n.2, p. 119-122, 1994.

5. Cubero, J.; Graham, J. H. Genetic relationship among worldwide strains of Xanthomonas causing canker in citrus species and design of new primers for their identification by PCR. Applied and Environmental Microbiology, Washington, v. 68, n. 3, p.12571264, 2002.

6. Dornelles, C. M. M. O problema da queda de frutos jovens de citros no Rio Grande do Sul. In: MESA Redonda para Estudo da Queda de Frutos Jovens em Citrus, 1977, Taquari, RS: p.3-6.

7. Feichtenberger, E. Queda de frutos jovens em citros. Laranja, Cordeirópolis, v.12, n. 2, p. 513-521, 1991.

8. Ferreira, J. H. S.; Matthee, F.N.; Thomas, A. C. Biological control of Eutypa lata on grapevine by an antagonistic strain of Bacillus subtilis. Phytopathology, St. Paul, v.81, p.283-287, 1991.

9. Goes, A. de; Graça, J.; Barros, J. C. S. M. de; Pinheiro, J. E. Controle de pinta preta em frutos de tangerina 'Rio' (Citrus deliciosa) ocasionada por Phyllosticta citricarpa. Fitopatologia Brasileira, Brasilia, v.15, n.1, p.73-5, 1990.

10. Gordon, R.E. The genus Bacillus. In: O'Leary, W. Pratical handbook of microbiology-bergey's manual. Boca Raton: CRC, 1990. p.109-126.

11. Kalita, P.; Bora, L.C.; Bhagabati, K.N. Phylloplane microflora of citrus and their role in management of citrus canker. Indian Phytopathology, New Delhi, v. 49, n. 3, p.234-237, 1996.

12. Kiely, T. B. Control and epiphytology of black spot of citrus on the central coast of New South Wales. New South Wales: Department of Agriculture Science Bulletin, 1948a. p.88.

13. Kiely,T. B. Preliminary studies on Guignardia citricarpa n.sp.: the ascigenous stage of Phoma citricarpa McAlp. and its relation to black spot of citrus. Proceedings of the Linnean Society of New South Wales, London, v. 73, p.249-92, 1948 b.

14. Kotzé, J. M. Studies on the black spot diseases of citrus caused by Guignardia citricarpa Kiely, with particular reference to its epiphytology and control at Labata. $1963.143 \mathrm{f}$. Tese (Science of Agriculture) - University of Pretoria, Pretoria.

15. Kotzé, J. M. Black spot. In: Whiteside, J. O.; Garnsey, S. M.; Timmer, L. W. Compendium of citrus diseases. 2. ed. St. Paul: APS, 1988, p.10-12.

16. Kumar, S.; Tamura, K.; Jakobsen, I. B.; NEI, M. Assess: MEGA 2: Molecular Evolutionary Genetics Analysis software, Arizona State University, Tempe, Arizona, USA. 2001. Free program distributed by the authors over the Internet from the website < http:// www.megasoftware.net>. Acesso em: 12 set. 2005.

17. Kupper, K. C.; Bettiol, W.; Corrêa, E. B.; Moretto, C. Potencialidade de Bacillus subtilis e Trichoderma spp. como agentes de 
biocontrole de Guignardia citricarpa. Fitopatologia Brasileira, Brasilia, v. 29: S129, 2004. (Abstract).

18. Kupper, K. C.; Bettiol, W.; Corrêa, E. B.; Moretto, C.; Goes, A. de Controle de Guignardia citricarpa, agente causal da mancha preta dos frutos cítricos, através de Bacillus subtilis e Trichoderma spp., Congreso Latinoamericano de Fitopatologia, 12. Taller de la Asociación Argentina de Fitopatólogos, 3.Córdoba. 2005. Libro de Resúmenes.

19. Kupper, K. C.; Gimenes-Fernandes, N. Isolamento e seleção de Bacillus spp. para o controle de Colletotrichum acutatum em flores destacadas de lima ácida 'Tahiti'. Summa Phytopathologica, Botucatu, v. 28, n. 3, p.292-295, 2002.

20. Kupper, K. C.; Gimenes-Fernandes, N.; Goes, A. de Controle biológico de Colletotrichum acutatum, agente causal da queda prematura dos frutos cítricos. Fitopatologia Brasileira, Botucatu, v. 28, n.3, p. 251-257, 2003.

21. Prates, H. S.; Nogueira, N. L. Controle químico da pinta preta (Phyllosticta citricarpa) em laranjeiras Pêra. In: Congresso Paulista de Fitopatologia, 20. 1996, São Paulo. Programas e Resumos. São Paulo: Grupo Paulista de Fitopatologia, 1997.p.89.

22. Pusey, P. L.; Wilson, C. L.; Hotchkiss, M. W.; Franklin, J. D. Compatibility of Bacillus subtilis for postharvest control of pe- ach brown rot with comercial fruit waxes, dicloran, and coldstorage conditions. Plant Disease, St. Paul, v.70, n. 6, p. $587-$ $590,1986$.

23. Restrepo, S.; Vélez, C. M.; Verdier, V. Measuring the genetic diversity of Xanthomonas axonopodis pv. manihotis within different fields in Colombia. Phytopathology, St. Paul, v. 90, n. 7, p. 683-690, 2000.

24. Saitou, N.; Nei, M. The neighbor-joining method: A new method for reconstructing phylogenetic trees. Molecular Biology and Evolution, Oxford, v. 4, p. 406-425, 1987.

25. Sambrook, J.; Maniatis, T.; Fritsh, E. F. Molecular cloning: a laboratory manual 2. ed. New York: Cold Sprig Harbor Laboratory, 1989.

26. Shillito R. D.; Saul, M. W. Protoplast isolation and transformation. In: Shaw, C. H. (ed). Plant molecular biology: a practical approach. IRL Press: Oxford, 1988. p. 161-186.

27. Sonoda, R.M.; Guo, Z. Effect of spray applications of Bacillus subtilis on postbloom drop of citrus. Phytopathology, St. Paul, v. 86, n. 11, p.S52, 1996.

28. Swofford, D. L. PAUP*. Phylogenetic Analysis Using Parsimony (*and Other Methods), 4 ed. Florida: Sinauer, Sunderland, 2002. 1 CD-ROM. 